\title{
Studies on the fibrinolytic enzyme system in obesity
}

\author{
N. B. BENNETT, C. M. OgSTON, G. M. McANDREW, AND D. OGSTON
}

From the Department of Medicine, University of Aberdeen, and Aberdeen Royal Infirmary

SYNOPSIS Plasma fibrinolytic activity, inhibitors of fibrinolysis, and fibrinogen were estimated in 34 subjects of varying ratio of observed to standard weight. The inverse relationship between fibrinolytic activity and the ratio of observed to standard weight was confirmed. No significant correlation was found between anti-plasmin or anti-urokinase and the ratio of observed to standard weight. It was therefore concluded that the decreased plasma fibrinolytic activity in obese subjects is due to decreased production of plasminogen activator rather than to excessive inhibition.

Several investigators have shown that blood fibrinolytic activity is diminished in obesity (Goldrick, 1961; Shaw and MacNaughton, 1963; Fearnley, Chakrabarti, and Avis, 1963). We have previously reported a study confirming that fibrinolytic activity is reduced in obese subjects and showing that this reduction is not due to plasminogen deficiency (Ogston and McAndrew, 1964). We have examined a further group of subjects of varying observed/ standard weight ratio to determine the role of inhibitors of fibrinolysis in this reduction.

\section{METHODS AND MATERIALS}

PLASMA FIBRINOLYTIC ACTIVITY Euglobulin clot lysis times were estimated by the method of Nilsson and Olow (1962) and expressed by plotting the values logarithmically against units of fibrinolytic activity (Sherry, Lindemeyer, Fletcher, and Alkjaersig, 1959), 10 units being arbitrarily equated with a lysis time of 50 minutes. Times of over 500 minutes were taken as 1 unit. Such a technique has been shown to correlate well with specific assays of plasminogen activator (Fletcher, Biederman, Moore, Alkjaersig, and Sherry, 1964).

PLASMA FIBRINOGEN Fibrinogen was assayed by a modification of the method of Ratnoff and Menzie (1951).

ANTI-PLASMIN Anti-plasmin was estimated by the technique of Alkjaersig, Fletcher, and Sherry (1959) using activator-free plasmin prepared by auto-activation of plasminogen in $50 \%$ glycerol. The plasminogen used to prepare the plasmin was obtained from Kabi Pharmaceuticals Ltd.

Received for publication 10 January 1966.
PLASMINOGEN-ACTIVATOR INHIBITOR This inhibitor was measured by determining the power of serum to inhibit lysis of a standard clot by the plasminogen-activator urokinase. The results are expressed as units of urokinase inhibited by the serum sample under the conditions of the assay. The urokinase was obtained from Leo Laboratories Ltd.

ASSESSMENT OF OBESITY The ratio of observed to standard weight was calculated from the weight-for-height standards of Kemsley, Billewicz, and Thomson (1962).

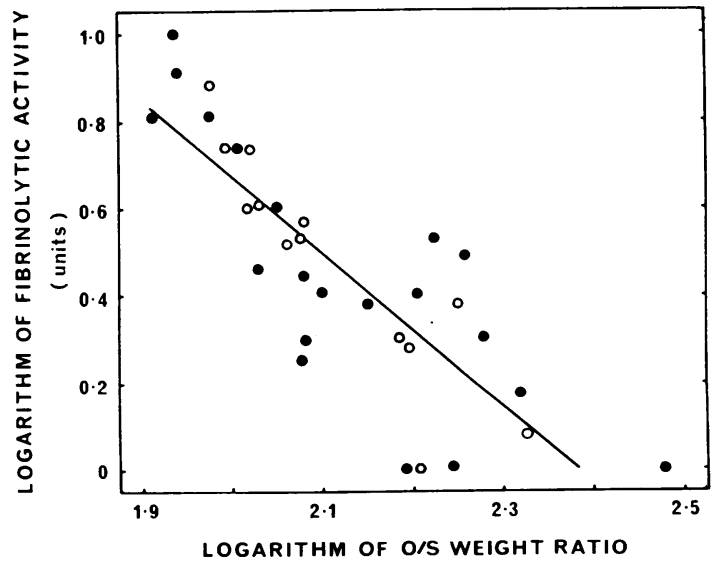

FIG. 1. Relationship between fibrinolytic activity and observed/standard weight ratio (regression $y=4.17$ $1.75 x)$ 


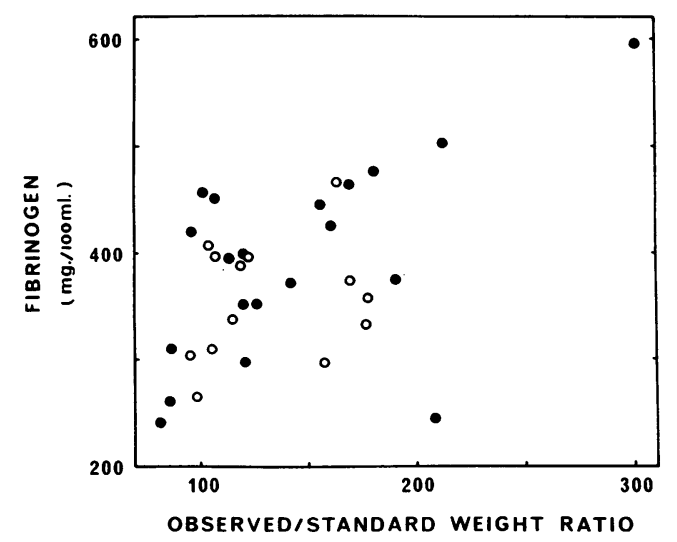

FIG. 2. Relationship between plasma fibrinogen and observed/standard weight ratio.

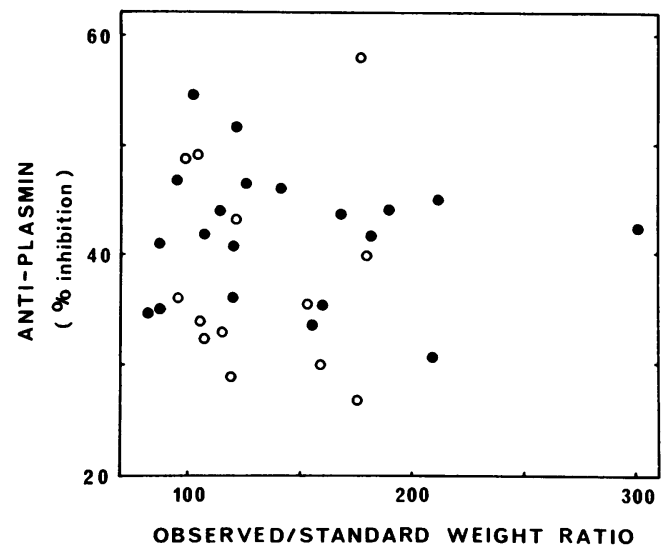

FIG. 3. Relationship between anti-plasmin and observed/ standard weight ratio.

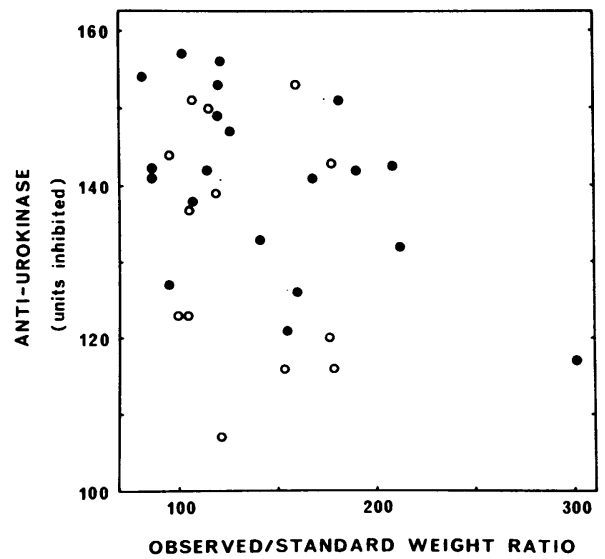

FIG. 4. Relationship between anti-urokinase and observed/standard weight ratio.
SUBJECTS The 34 subjects (14 males and 20 femal studied consisted of convalescent hospital patients wh minor disorders and patients admitted to hospital foir weight reduction. In two of these subjects all the estim $\overline{\bar{a}}-$ tions were not performed. The age range was 16-78 years (mean 46). All were confined to bed for at least 12 houfs before venepuncture which was carried out betwe 8 and 9 a.m.

\section{RESULTS}

The relationship between fibrinolytic activity and t observed/standard weight ratio was curvilinear; the logarithmic transformation is shown in Fig. This is a highly significant linear relationship ( $\mathrm{r} \stackrel{\mathrm{O}}{\mathrm{O}}$ $-0.82 ; p<0.001)$. Figure 2 shows the correlation between plasma fibrinogen and the $\mathrm{O} / \mathrm{S}$ weight ratio $(\mathrm{r}=+0.51 ; \mathrm{p}<0.01)$. The relationship between fibrinolytic activity and fibrinogen level was less marked $(r=-0.39 ; p<0.05)$.

Figures 3 and 4 present the anti-plasmin and anti-urokinase levels plotted against the $\mathrm{O} / \mathrm{S}$ weight ratio. No relationship was present: for anti-plasmin $r=+0.02(p<0.1) ;$ for anti-urokinase $r=-0.25$ (p $<0.1)$. It is concluded that obesity is n\&t associated with increased blood levels of inhibitofs of fibrinolysis.

\section{CONCLUSION}

In this study we have confirmed that blood fibrino:lytic activity, measured by the euglobulin clot lysis time, is reduced in obesity (Ogston and McAndre $\overrightarrow{8}$, 1964) and have again found some association between obesity and increased plasma fibrinogen levels. T留 euglobulin lysis time is primarily a measure af plasminogen activator since the inhibitors of fibringlysis, anti-plasmin, and probably anti-activator (Bennett, 1965) are not included in the euglobulu fraction. We have found that there is no increase anti-plasmin or anti-urokinase (used as a measure of anti-activator) in the blood of obese subjects.

Until more information about activator inhibitooss is available, we conclude that the low blood firrinolytic activity found in obesity is due to decreased production of plasminogen activator rather than excessive inhibition.

We are grateful to Professor H. W. Fullerton for helpewl advice in the preparation of this paper, and Dr. T. Morgan for permission to study patients in his care.

This study was supported by a grant from the Tobaç्क Research Council of Great Britain on the recommendation of the British Heart Foundation, and by the Medicgl Research Council.

\section{REFERENCES}

Alkjaersig, N., Fletcher, A. P., and Sherry, S. (1959). J. clin. Inveß, 38, 1086.

Bennett, N. B. (1965). Unpublished observations. 
Fearnley, G. R., Chakrabarti, R., and Avis, P. R. D. (1963). Brit. med. J., 1, 921.

Fletcher, A. P., Biederman, O., Moore, D., Alkjaersig, N., and Sherry, S. (1964). J. clin. Invest., 43, 681.

Goldrick, R. B. (1961). Aust. Ann. Med., 10, 20.

Kemsley, W. F. F., Billewicz, W. Z., and Thomson, A. M. (1962). Brit. J. prev. soc. Med., 16, 189.
Nilsson, I. M., and Olow, B. (1962). Acta chir. scand., 123, 247.

Ogston, D., and McAndrew, G. M. (1964). Lancet, 2, 1205.

Ratnoff, O. D., and Menzie, C. (1951). J. Lab. clin. Med., 37, 316.

Shaw, D. A., and MacNaughton, D. (1963). Lancet, 1, 352.

Sherry, S., Lindemeyer, R. I., Fletcher, A. P., and Alkjaersig, N. (1959). J. clin. Invest., 38, 810.

\section{Broadsheets prepared by the Association of Clinical Pathologists}

The following broadsheets (new series) are published by the Association of Clinical Pathologists. They may be obtained from Dr. R. B. H. Tierney, Pathological Laboratory, Boutport Street, Barnstaple, N. Devon. The prices include postage, but airmail will be charged extra.

13 The Identification of Serotypes of Escherichia coli Associated with Infantile Gastro-enteritis. 1956. JOAN TAYLOR. $1 \mathrm{~s}$.

16 Preservation of Pathological Museum Specimens. 1957. L. W. PROGER. 1s.

17 Cultural Diagnosis of Whooping-cough. 1957. B. W. LACEY. $1 \mathrm{~s}$.

20 Investigation of Porphyrin/Porphyria. 1958 (reprinted 1962). C. RIMINGTON. 2s.

23 The Dried Disc Technique for Bacterial Sensitivity Tests. 1959. R. W. FAIRBROTHER and J. C. SHERRIS. 1s.

24 Safe Handling of Radioactive Tissues in the Laboratory and Post-mortem Room. 1959. R. C. CURRAN. 1s.

26 The Periodic Acid-Schiff Reaction. 1959. A. G. E. PEARSE. 1s.

28 Daily Fatty Acid Excretion. 1960. A. C. FRAZER. 2 s.

29 The Preparation of Bone for Diagnostic Histology. 1960. D. H. COLLINS. 2s.

30 Control of Accuracy in Chemical Pathology. 1961. G. H. GRANT. $4 \mathrm{~s}$.

31 Investigation of Haemorrhagic States with Special Reference to Defects of Coagulation of the Blood. 1961. E. K. BLACKBURN. 4s.

32 Detection of Resistance to Streptomycin, P.A.S., and Isoniazid in Tubercle Bacilli. 1961. R. CRUICKSHANK and S. M. STEWART. 2 s.

33 The Laboratory Detection of Abnormal Haemoglobins. 1961 (reprinted 1965). H. LEHMANN and J. A. M. AGER. 4s.

34 Titration of Antistreptolysin O. 1961. H. GOODER and R. E. O. WILliams. $2 \mathrm{~s}$.

35 The Estimation of Faecal 'Urobilinogen'. 1961. C. H. GRAY. 2s.
36 Quantitative Determination of Porphobilinogen and Porphyrins in Urine and Faeces. 1961. C. RIMINGTON. 3s. 6d.

37 The Paper Electrophoresis of Serum and Urinary Proteins. 1961. G. FRANGLEN and N. H. MARTIN. 4s.

38 The Augmented Histamine Gastric Function Test. 1961. M. LUBRAN. 2s.

39 Investigation of Haemolytic Anaemia. 1961. J. G. SELWYN. 2s.

40 Short-term Preservation of Bacterial Cultures. 1962. E. JOAN STOKES. $2 s$.

41 Serological Tests for Syphilis. 1962. A. E. WILKINson. 6s.

42 The Determination of Glucose 6-Phosphate Dehydrogenase in Red Cells. 1962. T. A. J. PRANKERD. $2 \mathrm{~s}$.

43 Mycological Techniques. 1962. R. W. RIDDELL. 3s. $6 \mathrm{~d}$.

44 The Laboratory Investigation of Catecholamine Secreting Tumours. 1963. M. SANDLER and C. R. J. RUTHVEN. 2s.

45 Diagnostic Test for Hereditary Galactosaemia. 1963. v. SCHWARTZ. 2 s.

46 The Determination of Serum Iron and Total Iron Binding Capacity. 1963. A. JORDAN and D. A. PODMORE. 2s.

47 Nuclear Sexing. 1964. B. LENNOX and W. M. DAVIDSON. 2 s.

48 The Laboratory Investigation and Control of the Defibrination Syndrome. 1964. R. M. HARDISTY, G. I. C. INGRAM, and A. A. SHARP. 3s. 6d.

49 Rapid Diagnostic Section Technique. 1965. N. J. BROWN and A. T. SANDISON. 2 s.

50 The Collection, Preservation and Staining of Specimens for Gynæcological Cytology. 1965. ERICA WACHTEL. 4s. 